\title{
Physical activity and kidney diseases
}

\author{
Silvio Maringhini \\ From 70th Congress of the Italian Society of Pediatrics, Joint National Meeting SIP, SICuPP, SITIP \\ Palermo, Italy. 11-14 June 2014
}

Regular physical activity (PA) in the early school years is recommended by several scientific associations for primary prevention of cardiovascular disease. Long-term observational studies have shown that subjects who exercise regularly have significantly less coronary heart disease (CHD) and a reduced risk of cardiovascular disease (CVD). Exercise reduces serum triglycerides, increases serum high density lipoprotein-cholesterol, lowers the blood pressure in patients with primary hypertension [1]. Regular exercise reduces the production of atherogenic cytokines and increases production of atheroprotective cytokines. It should be mentioned, however, that other factors may be associated with physical activity (e.g. a healthy diet, avoiding cigarette smoking, regular medical care) and may contribute to the improved health. No long term studies have been produced on the effects of PA during childhood on CHD and CVD in adult life but indirect evidence suggests that it may produce benefit.

Regular exercise, on the other end, is associated with potential adverse effects (eg, musculoskeletal injuries, arrhythmias, myocardial infarction, and rhabdomyolysis); however, the absolute risk of kidney disease during exercise is low [2]. Consensus guidelines for the pre-participation physical evaluation (PPE) suggest a PPE for all children, even those who do not participate in organized sports, as an opportunity to promote health and fitness. PPE includes a medical and family history and a physical examination, with particular emphasis on the musculoskeletal and cardiovascular systems [3].

Exercise induces profound changes in the renal haemodynamics and in electrolyte and protein excretion. Proteinuria, hematuria and changes in serum electrolyte balance have been reported during intense PA; the increase in glomerular filtration may explain these transient alterations but the "nutcracker" compression on the renal vein may have a role. Haemoglobinuria and myoglobinuria may be observed under special exercise conditions [4].
PA does not worse nor reverse kidney disease but may reduce cardiovascular risk in chronic renal disease [5]. Children on dialysis and after a renal transplantation performing aerobic physical exercise show improvements in exercise tolerance, in quality of health and uraemic symptom scores; they gain weight loss, cardiovascular reactivity, avoiding an increase in blood pressure medication [6].

Published: 11 August 2014

\section{References}

1. Spagnolo A, Giussani M, Ambruzzi AM, Bianchetti M, Maringhini S, Matteucci MC, Menghetti E, Salice P, Simionato L, Strambi M, Virdis R, Genovesi S: Focus on prevention, diagnosis and treatment of hypertension in children and adolescents. Ital J Pediatr 2013, 39:20.

2. Grinsell MM, Butz K, Gurka MJ, Gurka KK, Norwood V: Sport-related kidney injury among high school athletes. Pediatrics 2012, 130:e40-5.

3. Giordano M: Participation in sports by children and adolescents with chronic kidney disease. G Ital Nefrol 2012, 29:328-32.

4. Poortmans JR: Exercise and renal function. Sports Med 1984, 1:125-53.

5. Manfredini F, Mallamaci F, Catizone L, Zoccali C: The burden of physical inactivity in chronic kidney disease: is there an exit strategy? Nephrol Dial Transplant 2012, 27:2143-5.

6. Lubrano R, Tancredi G, Bellelli E, Gentile I, Scateni S, Masciangelo R, De Castro G, Versacci P, Elli M: Influence of physical activity on cardiorespiratory fitness in children after renal transplantation. Nephrol Dial Transplant 2012, 27:1677-81.

doi:10.1186/1824-7288-40-S1-A21

Cite this article as: Maringhini: Physical activity and kidney diseases. Italian Journal of Pediatrics 2014 40(Suppl 1):A21.

\footnotetext{
Pediatric Nephrology Unit. "G. Di Cristina" Children's Hospital. A.R.N.A.S. Palermo. Via Benedettine 2, 90134 Palermo, Italy
} 